\title{
Long-term survival in idiopathic pulmonary arterial hypertension associated with massive pulmonary artery dilation
}

\author{
Vanja Petrovic MD, Christopher J Ryerson MD FRCPC, Robert D Levy MD FRCPC
}

\begin{abstract}
V Petrovic, CJ Ryerson, RD Levy. Long-term survival in idiopathic pulmonary arterial hypertension associated with massive pulmonary artery dilation. Can Respir J 2011;18(3):e50-e51.

The present report describes two patients with long-term survival after being diagnosed with idiopathic pulmonary arterial hypertension more than 20 years earlier. Both patients were treated with calcium channel blockers for several years and are currently maintained on bosentan, an oral endothelin receptor antagonist. Severe dilation of the main pulmonary arteries is present in both patients and may be related to long-term survival with idiopathic pulmonary arterial hypertension.
\end{abstract}

Key Words: Idiopathic pulmonary arterial hypertension; IPAH; Pulmonary artery dilation; Survival

\section{CASE PRESENTATIONS}

\section{Patient 1}

In 1988, a 62-year-old woman presented with progressive dyspnea on exertion. She had taken an unknown diet pill for one month approximately 30 years previously. She smoked until 1990, with a 45-pack-year history. She had two successful pregnancies, with one miscarriage. Physical examination revealed a loud pulmonic component of the second heart sound and a grade 2 systolic murmur at the left sternal border. The echocardiographic estimate of pulmonary artery systolic pressure (PASP) was $83 \mathrm{mmHg}$. Echocardiography also demonstrated right ventricular hypertrophy and moderate tricuspid regurgitation. Pulmonary arterial hypertension $(\mathrm{PAH})$ was confirmed by cardiac catheterization. Extensive further investigations failed to identify an associated condition that could have resulted in pulmonary hypertension $(\mathrm{PH})$.

The patient was diagnosed with idiopathic PAH (IPAH) and treated with calcium channel blockers for 17 years. She exhibited good clinical response and was again able to play 18 holes of golf, walking the course. Subsequent echocardiograms demonstrated persistent $\mathrm{PH}$ despite good clinical response.

In 2004, the patient developed WHO class III dyspnea, reflected by a reduced 6 min walk distance of $350 \mathrm{~m}$. A computed tomography (CT) scan showed markedly dilated pulmonary arteries with an organized intraluminal clot (Figure 1A). In 2005, the patient began chronic oral anticoagulation and bosentan therapy, which led to improvement of her dyspnea symptoms to WHO class II.

\section{Patient 2}

In 1984, a 52-year-old nonsmoking man presented with progressive dyspnea. He worked as an automobile mechanic, and wore a mask when using aerosolized products. Echocardiography and cardiac catheterization revealed $\mathrm{PH}$, with a PASP of greater than $80 \mathrm{mmHg}$. Extensive investigations did not identify a related cause and he was treated with hydralazine, captopril and verapamil for presumed IPAH.

He experienced stable symptoms for more than 20 years; however, in 2006, he developed worsening WHO class III dyspnea, reflected by a reduced 6 min walk distance of $276 \mathrm{~m}$. His oxygen saturation was $94 \%$ on room air. Precordial examination revealed a loud pulmonic

\section{La survie à long terme en cas d'hypertension artérielle pulmonaire idiopathique associée à une dilatation artérielle pulmonaire massive}

Le présent rapport décrit deux patients qui survivent depuis plus de 20 ans à un diagnostic d'hypertension artérielle pulmonaire idiopathique. Les deux patients ont été traités au moyen d'inhibiteurs calciques pendant plusieurs années et prennent désormais un traitement d'entretien au bosentan, un antagoniste des récepteurs de l'endothéline par voie orale. On constate une dilatation marquée des principales artères pulmonaires chez les deux patients, peut-être liée à la survie prolongée malgré l'hypertension artérielle pulmonaire idiopathique.

heart sound and left parasternal heave. There was trace peripheral edema. A CT scan revealed massive dilation of the pulmonary arteries with chronic mural thrombus in the right pulmonary artery (Figure 1B). $\mathrm{CT}$ angiography and repeat ventilation perfusion scans were not suggestive of chronic thromboembolic disease. Repeat right heart catheterization showed pulmonary artery systolic, diastolic, and mean pressures of $82 \mathrm{mmHg}, 48 \mathrm{mmHg}$ and $61 \mathrm{mmHg}$, respectively. The right atrial pressure was $3 \mathrm{mmHg}$ and pulmonary capillary wedge pressure was $11 \mathrm{mmHg}$. A vasodilator challenge was not performed. The patient was treated with bosentan and warfarin, which led to symptomatic improvement to WHO class II. Echocardiography showed improvement in PASP to $50 \mathrm{mmHg}$.

Both patients currently remain stable on bosentan and anticoagulants.

\section{DISCUSSION}

The revised WHO classification of $\mathrm{PH}$ includes five major subtypes of $\mathrm{PH}$, including PAH (1). PAH can be further subdivided into IPAH, previously known as primary pulmonary hypertension, or PAH related to several other etiologies. IPAH is, therefore, a diagnosis of exclusion.

The United States prospective registry for IPAH $(2,3)$ reported a median survival of only 2.8 years, with an estimated five-year survival rate of $34 \%$ without treatment. A similar registry from the United Kingdom (4) documented a median survival of 3.4 years. Although IPAH is generally progressive and fatal, there is considerable variability in survival. Many patient characteristics correlate with prognosis, including functional class, rapidity of onset and exercise capacity. Several hemodynamic variables and markers of right ventricular function also predict increased risk of death including increased right atrial pressure and size, increased mean pulmonary arterial pressure, acute vasodilator responsiveness, decreased cardiac index, and right ventricular enlargement or dysfunction (1-3).

There are few reports of long-term survival in IPAH. Two previous reports including three patients with IPAH reported stable disease for more than 25 years $(5,6)$; however, the mean pulmonary arterial pressure at diagnosis was less than $50 \mathrm{mmHg}$ in all three patients. In the current report, we present two additional cases of severe IPAH with an unusually long survival of 21 and 25 years after diagnosis, respectively. 


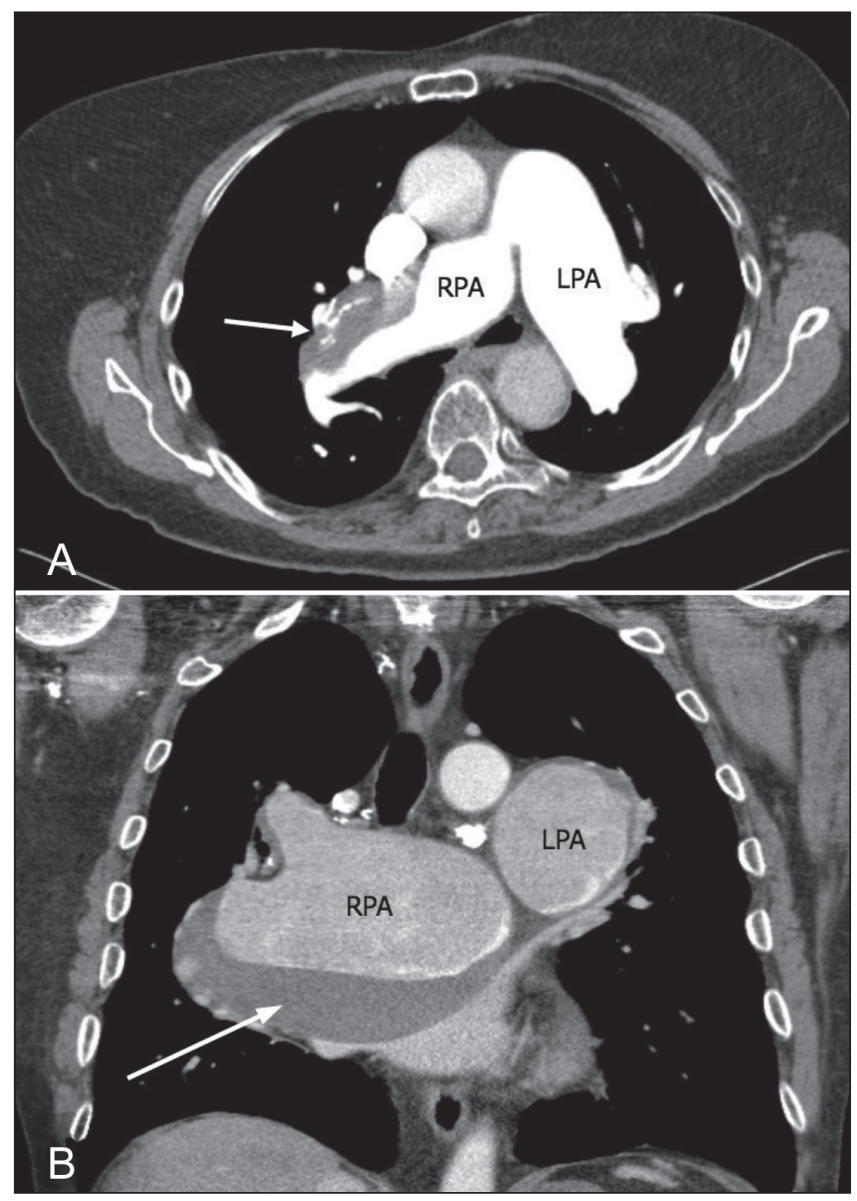

Figure 1) A Patient 1. Computed tomography scan with intravenous contrast demonstrating dilation of the right pulmonary artery (RPA, $4.6 \mathrm{~cm}$ ) and left pulmonary artery (LPA, $4.3 \mathrm{~cm})$. An intraluminal filling defect (arrow) is seen in the RPA, measuring $6.8 \mathrm{~cm} \times 2.3 \mathrm{~cm}$ in maximal dimension. The presence of internal calcification and stability of this mass for more than three years suggested that this filling defect was an organized clot. B Patient 2. Computed tomography scan demonstrating severe dilation of the RPA $(8.3 \mathrm{~cm})$ and LPA $(4.6 \mathrm{~cm}) . A$ mural thrombus is seen within the RPA (arrow)

Several explanations for improved survival may be possible. First, it is likely that some patients diagnosed with IPAH may have PAH related to another unrecognized condition, which may be associated with slower progression. It is recognized that all patients with IPAH do not share the identical pathological process. A study of 156 cases of IPAH conducted in 1970 (7) found that only two-thirds of patients had IPAH based on postmortem analysis. The rest of the patients had other causes of PH such as thromboembolic disease, sarcoidosis or connective tissue disease. Current diagnostic tests have likely improved this diagnostic accuracy; however, some patients may still be misdiagnosed as having IPAH.

Second, it is possible that our patients experienced recurrent pulmonary emboli. Both patients had improvement in symptoms with the addition of warfarin; however, extensive investigations did not support pulmonary emboli as the cause of deterioration. We hypothesize that the improvement in symptoms was due to the simultaneous addition of bosentan; however, it remains possible that treatment of undiagnosed pulmonary emboli with anticoagulation was instead responsible for this improvement. Observational data support a role for systemic anticoagulation therapy in IPAH; however, these data have not been confirmed in a well-designed randomized placebo-controlled trial (8). Furthermore, both patients initially experienced long-term benefits from calcium channel blocker therapy, which in itself, is associated with a favourable prognosis.

Third, the difference in survival may reflect genetic differences. For example, it is known that mutations in the BMPR2 gene are responsible for many cases of inherited and some sporadic forms of PAH (9). It is possible that additional mutations have disease modifying actions that influence survival.

Finally, patients with severe IPAH may possess adaptive physiology that could alter survival. For example, both of our patients exhibited marked pulmonary artery dilation. This remodelling of pulmonary vasculature may represent a compensatory adaptive response to high pulmonary artery pressures and an attempt to optimize hemodynamics and reduce right heart dysfunction. Pulmonary arterial capacitance (PAC) describes the degree to which the pulmonary arterial tree dilates during systole. Therefore, PAC is inversely proportional to the workload of the right heart. PAC has been demonstrated to be an independent predictor of mortality in IPAH (10). It could be postulated that the dilation of the pulmonary arteries seen in our patients was also a reflection of increased total $\mathrm{PAC}$ that resulted in improved right ventricular function.

\section{SUMMARY}

We described two patients with a diagnosis of IPAH who exhibited survival well beyond that expected of patients with this condition. Both patients initially responded well to calcium channel blockers and, subsequently, to bosentan, but with concurrent marked dilation of the pulmonary arteries. The presence of this severe arterial dilation raises the possibility of an adaptive physiological response that leads to improved survival.

DISCLOSURES: The authors have no disclosures that pertain to the content of this article.

CONSENT: The patients described in this article provided written consent for the publication of this information.

\section{REFERENCES}

1. Simmonneau G, Robbins IM, Beghetti M, et al. Updated clinical classification of pulmonary hypertension. J Am Coll Cardiol 2009;54:S43-54.

2. D'Alonzo GE, Barst RJ, Ayres SM, et al. Survival in patients with primary pulmonary hypertension. Results from a national prospective registry. Ann Intern Med 1991;115:343-9.

3. Rich S, Dantzker DR, Ayres SM, et al. Primary pulmonary hypertension: A national prospective study. Ann Intern Med 1987;107:216-23.

4. Primary pulmonary hypertension. Case series from the United Kingdom. Chest 1994;105:29S-32S.

5. Halank M, Marx C, Hoeffken G. Long term survival in primary pulmonary hypertension. Heart 2004;90:e40.

6. Trell E. Benign idiopathic pulmonary hypertension? Acta Medica Scandinavica 1973;193:137-43.

7. Wagenvoort CA,Wagenvoort N. Primary pulmonary hypertension. A pathologic study of the lung vessels in 156 clinically diagnosed cases. Circulation 1970;42:1163.

8. Rich S, Kaufmann E, Levy PS. The effect of high doses of calcium-channel blockers on survival in primary pulmonary hypertension. N Engl J Med 1992;327:76-81.

9. Austin ED, Loyd JE, Phillips JA III. Genetics of pulmonary arterial hypertension. Semin Respir Crit Care Med 2009;30:386-98.

10. Mahapatra S, Nishimura R, Sorajja P, et al. Relationship of pulmonary arterial capacitance and mortality in idiopathic pulmonary arterial hypertension. J Am Coll Cardiol 2006;47:799-803. 


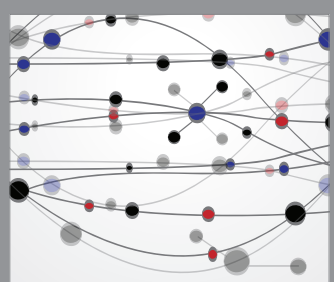

The Scientific World Journal
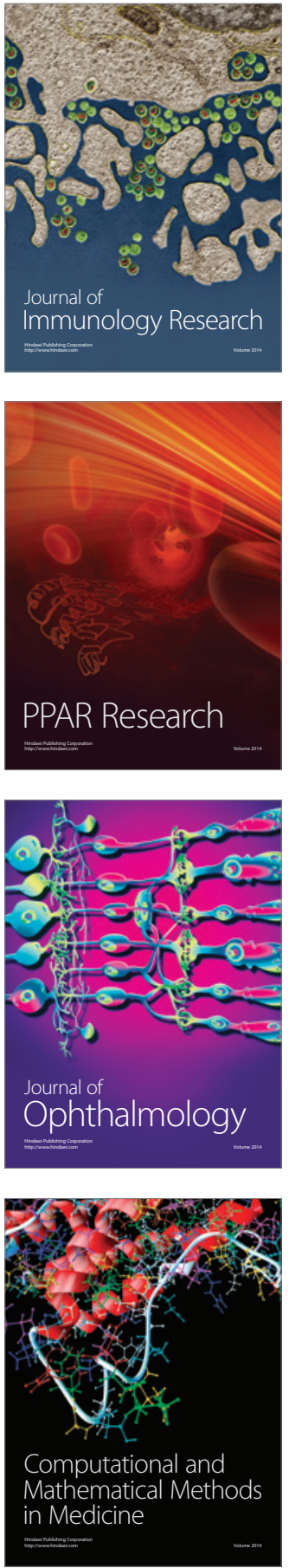

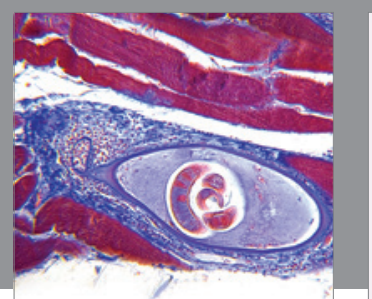

Gastroenterology Research and Practice

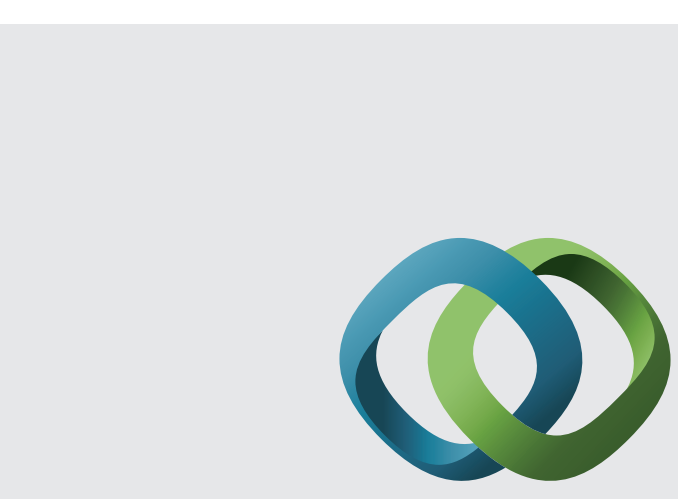

\section{Hindawi}

Submit your manuscripts at

http://www.hindawi.com
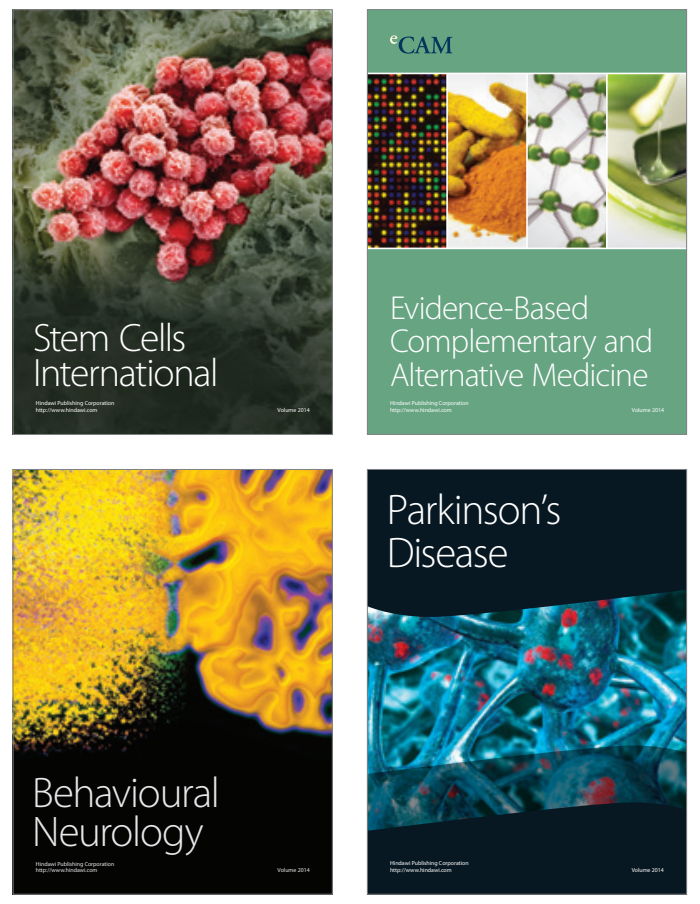
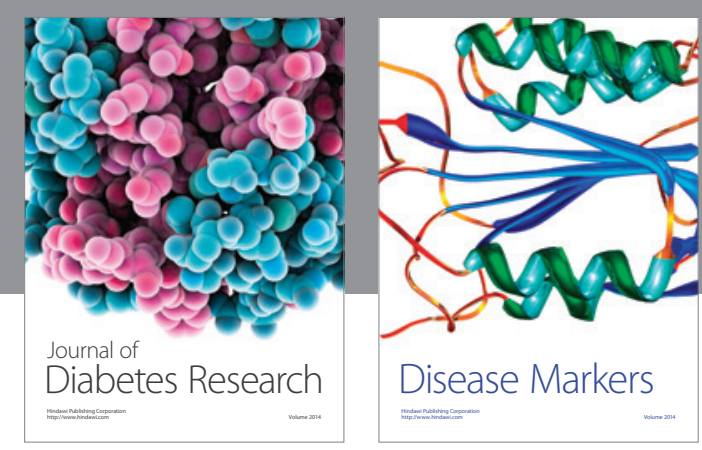

Disease Markers
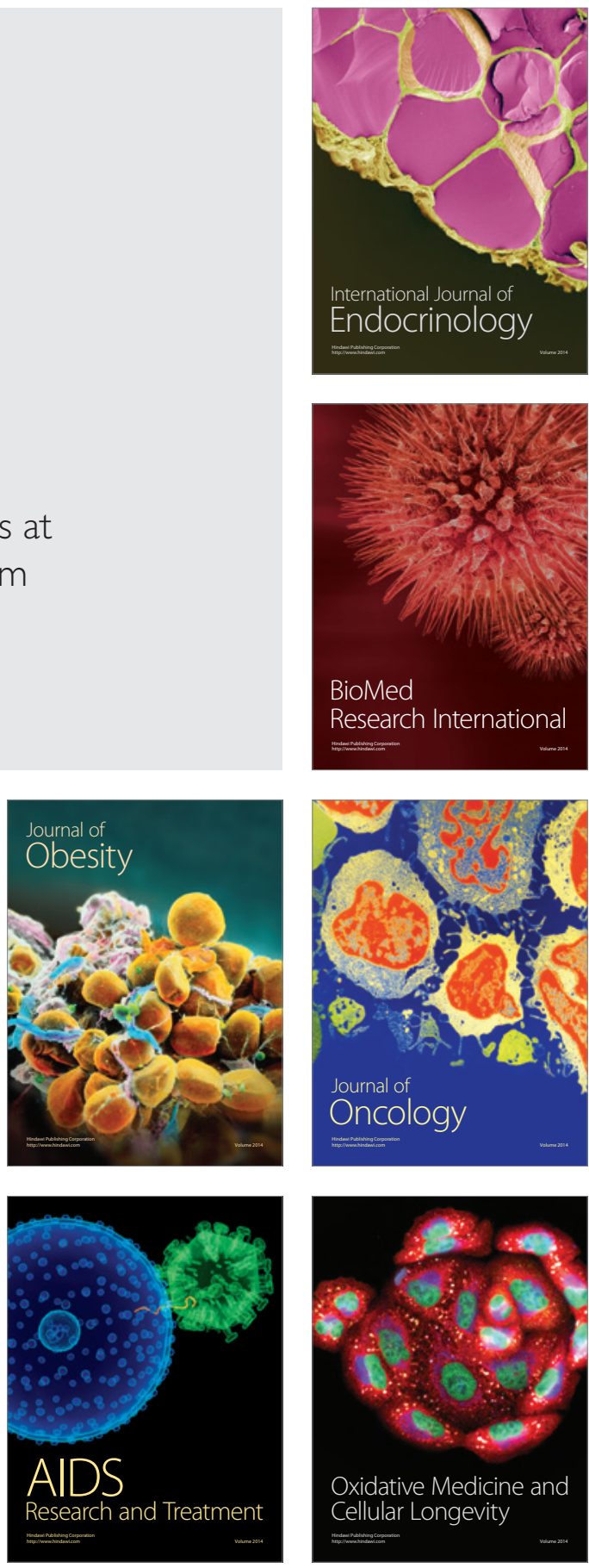